\title{
A Study of the Two-way Assessment System of Advertising Design Based on Occupational Demands
}

\author{
Weiwei $\mathrm{Yi}^{1, \mathrm{a}}$, Baijing Zou ${ }^{1, \mathrm{~b}}$, Yamei Wang ${ }^{1, \mathrm{c}}$ \\ ${ }^{1}$ Dalian Neusoft University, Dalian 116023, China

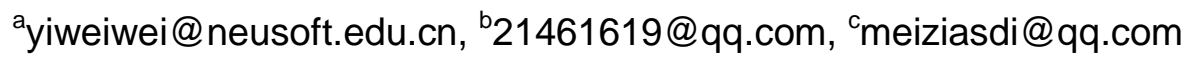

Keywords: advertising design; TOPCARES; CDIO; two-way; assessment.

\begin{abstract}
In order to ensure the optimization of teaching quality and enhance students' professional quality, this paper puts forward a new way of assessment system in the course of advertising design. The innovation of this system is to break the traditional single assessment method, combining TOPCARES-CDIO talent training mode with the characteristics of advertising design course, further subdivided the traditional assessment methods examination's capabilities. The system stat from eight comprehensive ability index T, O, P, C, A, R, E, S, and divided into C, D, I, O four stages to investigate the teachers' teaching and students learning effect. It has the dual function of guidance and feedback, which makes the relationship between teaching and examination more closely. After three years of teaching practice, it is proved that this is a successful and meaningful teaching reform, and it can provide reference for the construction of the assessment system of most design courses.
\end{abstract}

\section{The Significance of Improving the Assessment System of the Advertising Design Course}

Most of the advertising design courses and the textbooks used just focus on the forms of expression, components, page layout and other formal aspects. Admittedly, an excellent designer should not go without "beauty"; however, he or she should not neglect the prerequisites of existence and the environment of survival of advertisements, misled into turning out "beautiful nothing". The ultimate purpose of advertising is to get across information to the public for recognition through informing and persuading or to enhance a brand's perception for the public to purchase. Merely learning something that is formally beautiful far falls short of that goal. It also requires the designer to fulfill a series of tasks involving pre-project research, discussion of proposal, strategy-making, creative expression, making and implementation, system integration and operation and redevelopment. To successfully go through the flow, the designers are expected to have acquired solid professional expertise, along with other essential abilities involving innovation, teamwork, communication and market adoption. However, most advertisement design courses suffer deviations and limitations in fostering students' abilities, which has contributed to the gap between the students trained by universities and colleges and the talents really needed by the market. A number of educators have come to realize the problem and are seeking to introduce reforms. Yet the efforts are in the exploration stage without a clear orientation.

Advertisement design course has the characteristic of project type, the teacher as "supporting role", the student as "leading role". Students required autonomous learning and active participation, Emphasize the cultivation of students' professional accomplishment and professional ability. About course construction, in general, the basic skills as the main line, relying on actual or virtual projects to achieve the integration of teaching and production. In the course of teaching, teachers explained case first, and then give the practice project to students, students through information collection, program design, project implementation and final assessment to complete the task. Students through cooperation, understanding each professional knowledge point, master each professional skill. The most striking feature of advertising design course is "Take the project as the main line, the teacher as the guide, the student as the main body", the passive teaching mode of "teachers speak, students listen " is changed [1].

Course assessment serves as an essential link of instructional activities in university. Different manners of assessment make teachers adopt distinct options and schedules in terms of teaching 
contents and methods. In turn, students will adjust their learning methods according to the ways of assessment [2]. Therefore, a course reform can be undertaken starting from that of assessment. The traditional model of assessment is relatively independent and does not organically connect to the whole teaching process, which has long been criticized as a drawback. The common practice of the advertisement design course is just directed at the design link, a serious limitation. What's worse, students will be misled to think that advertisement design is just about the forms, which goes against the core mission of advertisement design serving the market. A more rational and scientific system of assessment combines the dual functions of orientation and feedback, not only immediately reflecting the teaching effects and encouraging teachers to optimize instructions but mobilizing the students' initiatives to learn comprehensively.

\section{Establishment of the Two-way Assessment System Featuring TOPCARES-CDIO}

In 2004, Massachusetts Institute of Technology in USA(MIT), Royal Institute of Technology in Sweden, Chalmers University of Technology and Linkoping University in Sweden co founded the CDIO engineering education model. Since 2005, Shantou University imported CDIO engineering education reform, and put into practice, CDIO engineering education model in China has developed for more than ten years. Thirty-nine institutions of higher learning learn from the CDIO model, set off a wave of teaching reform [3]. Engineering practices are divided into four links by CDIO, they are "conceive”, “design”, "implement” and "operate”. "Conceive” entails customer needs analysis, designing of technology and enterprise strategies and that of regulations and the establishment of development conception, technical procedures and business plans. "Design" mainly includes project plan, drawing designs and implementing plans. "Implement" specially refers to the process of turning designs into products, involving the validation of the manufacturing solution, the decoding scheme, test plan and the design proposal. "Operate" mainly means the assessment of the previous procedures by running a product, including the revision, modification and elimination of a system [4]. Dalian Neusoft University of Information (DNUI) made innovations on the CDIO model by introducing the concrete descriptions of abilities to be fostered. Thus the university constructed a TOPCARES-CDIO system featuring eight first-level ability indicators: technical knowledge and reasoning, open thinking and innovation, personal and professional skills, communication and teamwork, attitude and manner, responsibility, ethical values and social contribution by application practice [5].

Can the fresh teaching model characterized by TOPCARES-CDIO be applied to the advertisement design course? The conception of CDIO is aimed at giving solution to the combination of theory and practice in engineering instruction while the course in question comes under the category of art, which seems to be far apart from "engineering”. In fact, advertisement design carries the engineering characteristics in itself, differing from the traditional easel art. Instead, it is a discipline integrating artistry, practicality and technicality. The designing process is a systemic cycle with the aim of turning out advertisement products, it is in full agreement with the CDIO cycle of "conceive”, “design”, “implement” and "operate”, see Table 1. It can be seen that the TOPCARESCDIO teaching mode is suitable for the advertisement design course.

Table 1 The Advertisement Designing Process against the CDIO Life Cycle

\begin{tabular}{cccc}
\hline Conception & Designing & Implementation & Operation \\
\hline 1.Market Analysis & 1. Proposal & 1.Components & 1.Advertising delivery \\
2. Form Requirements & 2.Revision & Manufacturing & 2.Feedback \\
3. Goal Setting & 3. Proposal Conclusion & 2.Advertisement & 3.Improvement \\
& & Integration & \\
& & 3. Printing and Output \\
\end{tabular}

Advertising design courses need to be integrated; each training goal forms an organic whole. Each of these factors is related to the overall quality and comprehensive ability of the practitioner. It includes the relevance of knowledge, the relevance of theory and practice, and the multidisciplinary correlation. Therefore, Market orientation and customer demand are important features of career 
needs. [6].Based on the TOPCARES-CDIO teaching model, the two-way learning and assessment system aims to help students learn more comprehensively and teachers instruct more rationally, with a view of the characteristics of the advertisement design course. Here, the "two-way model" refers to the two-way horizontal and vertical assessment on the learning effects on the part of the students by stages and following the TOPCARES-CDIO abilities for the course of advertisement design according to the flow of advertisement design. The abilities were derived from the system of eight first-level ability indications. See Table 2 for the detailed model for assessment.

Table 2 Two-way Assessment Form for TOPCARES-CDIO Abilities of the Advertisement Design Course

\begin{tabular}{|c|c|c|c|c|}
\hline & Conceive & Design & Implement & Operate \\
\hline $\begin{array}{c}\text { Technical } \\
\text { Knowledge and } \\
\text { Reasoning }\end{array}$ & $\begin{array}{l}\text { Research } \\
\text { Proposal }\end{array}$ & Final Plan & $\begin{array}{l}\text { Production and } \\
\text { Output }\end{array}$ & Final Defending \\
\hline $\begin{array}{l}\text { Open Thinking } \\
\text { and Innovation }\end{array}$ & Proposal Analysis & Creative Sketch & Final Deliverables & $\begin{array}{l}\text { Development } \\
\text { Plan }\end{array}$ \\
\hline $\begin{array}{l}\text { Personal and } \\
\text { Professional } \\
\quad \text { Skills }\end{array}$ & Planning & Final Plan & Final Deliverables & $\begin{array}{l}\text { Development } \\
\text { Plan }\end{array}$ \\
\hline $\begin{array}{l}\text { Communication } \\
\text { and Teamwork }\end{array}$ & $\begin{array}{l}\text { Summary and } \\
\text { Report }\end{array}$ & Brainstorming & Progress Report & Final Defending \\
\hline $\begin{array}{l}\text { Attitude and } \\
\text { Manner }\end{array}$ & Project Proposal & Participation & Participation & Participation \\
\hline Responsibility & Project Proposal & Participation & Participation & Participation \\
\hline $\begin{array}{c}\text { Ethical Values } \\
\text { Social }\end{array}$ & Project Proposal & Participation & Participation & Participation \\
\hline $\begin{array}{l}\text { Contribution by } \\
\text { Application } \\
\text { Practice }\end{array}$ & Planning & Final Plan & Final Deliverables & $\begin{array}{l}\text { Development } \\
\text { Plan }\end{array}$ \\
\hline
\end{tabular}

The above table is passed on to the students before the commencement of the course. By reading it, the students can have a full understanding of the study objectives, tasks and the forms of assessment so that they are guided to plan their studies to avoid the blindness. On one hand, through assessment by stages in the process of teaching, students can learn more about their own limitations to make adjustments; on the other, teachers can know clearly where the students are and make adjustments for the rest of the instructions. By the end of the course the teachers process the data collected from the items in the table for statistics and analyze the results in all the links and for all the abilities. The results serve as a feedback and guide the next cycle of instructions, which will be manifested in the syllabus of the course. An assessment cycle is not complete until now. Otherwise, the assessment in the previous links will make no sense. A complete system of assessment is expected to take into account not only how to measure and record the results and the proportions of the formative and summative results but also which abilities should be involved in the process, which stages are better for assessment and the contents and methods. Each teacher can make supplements and adjustments to the system.

\section{Advantages and Challenges of the Two-way Assessment System}

\subsection{Advantages.}

Firstly, compared with the traditional or old-fashioned teaching practices which suffer a loose connection between teaching and assessment and whose results of assessment cannot objectively and realistically reflect the teaching effects, the TOPCARES-CDIO system in question centers on students' study and extends through the whole teaching process, becoming an essential part of it. This method breaks through the one-off practice, paying more attention to the specific data collected on each ability and in every stage. Thus, the results of each student are more precise and persuasive so that the students can make specialized efforts to give play to their advantages and 
make up for disadvantages, avoiding the drawback of "one limitation negates the overall achievements" in traditional education and corrects the unfair, haphazard and incomprehensive nature of the traditional assessment.

Secondly, compared with the traditional assessment which is just summative and which carries no substantial meaning in helping students with their studies, the TOPCARES-CDIO system centers on students' study and carries through the whole teaching process, explicitly displaying the stages characteristic of advertisement design and the abilities the course expects the students to foster. The assessment contents and the assessments in different links are more like a medical certificate that diagnoses students' learning results, showing their achievements and identifying their weak points so that they can examine themselves and make targeted improvements. Thus the students will take the initiative to learn and study.

Third, the result obtained by the traditional assessment method contributes little to the improvement of teaching. Actually, teaching and assessment of influence each other; improved evaluation method is an effective way of promoting teaching. Collecting and analyzing the data obtained from the Two-way Assessment System, to improve the teaching system of the course, this is the most important significance to create TOPCARES-CDIO Two-way Assessment System. For one thing, it helps teachers keep track of the students' learning situation in time, and to adjust the latter Teaching; for another, it benefits the overall curriculum construction and helps continuous improvement.

\subsection{Challenges.}

The two-way TOPCARES-CDIO learning and assessment system requires that teachers should transform their minds and instructional behaviors. According to different teaching content, the teacher should choose the appropriate assessment method, in order to improve the ability of students about autonomous learning, cooperative communication and hands-on practice [7]. It is hard for people to change something they are already used to and it is all the more difficult for the teachers who specialize in teaching art to shift from the traditional free assessment method to the new one with an engineering nature which will take more time and energy. At the beginning, it will pose a gigantic challenge. Therefore, it is advisable that they look at the issue in view of their own development and make bold reforms. Moreover, the university should stress the importance of the reform and encourage the teachers to engage themselves by providing resources, opportunities and incentives to break down the barriers to reform.

The statistics of the assessments are expected to be made full use of by the professional teachers. So many reforms have failed because the implementers just take them as formalities. They are more prone to do so when they have to deal with data. The solution requires the mental transformation on the part of the teachers. They should look ahead, fully aware of the constructive role of a complete and scientific assessment system in the course and even the whole major construction.

\section{Conclusion}

Advertisement design is a process of creating and materializing creative ideas, which requires the designer to have the ability to research and analyze skillful techniques in artistic expression, open and innovative thinking, a rich buildup of experience and an extensive cultural foundation. Since the requirements are diverse for the abilities of an advertisement designer, the construction of the course should go underway with a view of the social and cultural environment. The two-way TOPCARES-CDIO learning and assessment system has been constructed after a careful investigation of the development environment of advertisement design. It is based on long-term teaching experience and the scientific TOPCARES-CDIO conception. It both reflects the stages characteristic of advertisement design and makes specific the abilities already acquired or yet to be acquired.

At present, the application of two-way assessment system in advertising design courses is very good. It can not only reflect the teaching effect, results on the students scientific comprehensive and fair assessment, and can make the students learning direction is clear, reasonable arrangements for learning focus, make a clear direction for the teaching of the teacher, in a timely manner to improve 
the teaching means and methods, to achieve the effect of teaching benefits teachers as well as students. Teaching practice proves that this is a successful and meaningful teaching reform attempt.

Furthermore, it goes with the common features of the designing discipline, so it can serve as a reference for most courses in this discipline in creating their own assessment systems. At the same time, it inevitably suffers inefficiencies which need to be improved in teaching. Like the life cycle of CDIO, the system also needs to be constantly put through the cycle of conception, design, implementation and operation to maximize and optimize its role.

\section{References}

[1]. Shali Zhang, "Application and evaluation about project type teaching model in the teaching activities of advertising design," China Association of Staff and Workers Education and Vocational Training Association Proceedings of the 2015 Annual Excellent Scientific Research Award,” vol. 2, pp. 1-10, December 2015.(In Chinese)

[2]. Xu Yin, Jingfan Hu, and Hong Zhang, "Exploration of the Learning and Assessment Methods Based on the CDIO Model,”Higher Education Forum, February 2010, pp.24-25.(In Chinese)

[3]. Wenlong $\mathrm{Hu}$, "The development of engineering education in the era of innovation: challenges and countermeasures,” Research in Higher Education of Engineering, April 2016, pp.32-33.(In Chinese)

[4]. Shuowang Wang and Chengwen Hong, "CDIO: A Classical Educational Model of Massachusetts Institute of Technology-Interpretation of CDIO Syllabus," Journal of Technology College Education, April 2009, pp.116-117.(In Chinese)

[5]. Tao Wen, "Exploration and Construction of the Integrated Talents Training Model Based on the TOPCARES-CDIO Framework,” China Higher Education, July 2011, pp.41-43.(In Chinese)

[6]. Jianzhong Zha, Wensheng Xu, Xueyong Gu, Xiaomin Zhu, Yiping Lu, Mingcheng E, “Study and Practice of CDIO Model from Syllabus Build to Curricula Design," Research in Higher Education of Engineering, February 2013, pp.10-23.(In Chinese)

[7]. Cuifang Xing, Ying Li, and Jie Lv, "A course evaluation method for the whole course of the following diversified teaching mode,” Computer Education, February 2016, pp.102-105.(In Chinese) 